\title{
AGENDA AMBIENTAL NA ADMINISTRAÇÃO PÚBLICA - A3P: UM ESTUDO SOBRE A POTENCIALIDADE DE APLICAÇÃO NO MUNICÍPIO DE SÃO GONÇALO DO AMARANTE/RN
}

\author{
G. S. Rêgo ${ }^{1}$, H. C. D. Pimenta ${ }^{2}$, V. M. Saraiva ${ }^{3}$ \\ ${ }^{1,2}{ }^{3}$ Instituto Federal do Rio Grande do Norte (IFRN) - Campus Central \\ giovannirego@yahoo.com.br - handson.pimenta@ifrn.edu.br -vanda.saraiva@ifrn.edu.br
}

Artigo submetido em maio/2011 e aceito em setembro/2011

\section{RESUMO}

O presente estudo teve como objetivo analisar a situação da implantação da Agenda Ambiental na Administração Pública (A3P) nas secretarias de finanças, infraestrutura, saúde, meio ambiente e urbanismo do município de São Gonçalo do Amarante/RN. Quanto ao procedimento de campo, foi aplicado um questionário junto aos gestores da secretaria. Tal questionário foi estruturado em grupos variáveis analíticas de acordo da estrutura da A3P proposta pelo Ministério de Meio Ambiente, sendo eles: uso racional dos recursos, licitação sustentável, qualidade de vida no ambiente de trabalho, desempenho administrativo e sensibilização e capacitação dos servidores. Pelos resultados constatou-se que as variáveis com mais potencialidade de se trabalhar nas secretarias estudadas foram as variáveis do grupo uso racional dos recursos, associadas ao uso de materiais, água e energia e ao gerenciamento de resíduos, além da variável solicitação de materiais recicláveis nos processos licitatórios, precisam ser melhor abordadas em todas as secretarias estudadas. De forma geral, as secretarias com um melhor desempenho em relação à potencialidade de aplicação da A3P foram as secretarias de saúde e a de infraestrutura, pois já desenvolviam alguns programas de uso racional de recursos naturais, qualidade de vida no trabalho. Assim, com este estudo pretende-se instaurar um processo de construção de uma nova cultura institucional no município de São Gonçalo do Amarante/RN, visando à introdução de técnicas de educação ambiental com o intuito de conscientizar os servidores para a otimização dos recursos para o combate ao desperdício e para a busca de uma melhor qualidade do ambiente trabalho.

PALAVRAS-CHAVE: A3P, Controles Ambientais, Responsabilidade Social, Administração Pública.

\section{ENVIRONMENTAL AGENDA OF PUBLIC ADMINISTRATION - A3P: A STUDY ON THE POTENTIAL APPLICATION WITHIN SÃO GONÇALO DO AMARANTE-RN, BRAZIL}

\begin{abstract}
This study aimed to analyze the situation of public administration in order to implement the environmental agenda of public administration (A3P) within departments of Finance, Infrastructure, Health and Environmental and Urban Planning. It is an exploratory and applied survey which used as a collect information approach an interview with managers of the departments studied. In this interview, it was used a structured questionnaire in groups of variables according to the model of A3P proposed by Environment Ministry of Brazil, namely: rational resource usage; sustainable bidding; quality of life in the workplace; management performance, awareness and training of servers. Concerning the results, it was found that variables with more potential to work within the departments
\end{abstract}

studied were the group of variables related to rational resource usage, such as material, water and energy usage as well as waste management, besides that the variable "request recyclable materials in the bidding process" need to be better addressed in all departments. In general, the departments with a better potential application of A3P were Health and Infrastructure because they have been developing some programs of natural resource usage and quality in workplace. To Conclude, with this study, it is intended to establish a building process of a new institutional culture in São Gonçalo city council, in order to introduce environmental education actions to improve the awareness of server and to improve the resource usage as well as to avoid wastes, seeking a better quality of life.

KEY-WORDS: A3P, Environmental Control, Social Responsibility, Public Administration. 


\section{AGENDA AMBIENTAL NA ADMINISTRAÇÃO PÚBLICA - A3P: UM ESTUDO SOBRE A POTENCIALIDADE DE APLICAÇÃO NO MUNICÍPIO DE SÃO GONÇALO DO AMARANTE/RN}

\section{INTRODUÇÃO}

A situação do meio ambiente mundial desafia a diferentes atores a preservar os recursos naturais e ao mesmo tempo, possibilitar um desenvolvimento social justo, permitindo que a sociedade humana, atinja uma melhor qualidade de vida em todos os aspectos.

A sociedade como um todo, cidadãos, órgãos governamentais e não governamentais, é responsável por preservar o meio ambiente de forma a assegurar o bem coletivo que representa. Todavia, vale destacar que entre esses atores da sociedade, o governo assume um papel essencial já que é responsável pela articulação e criação de diversas políticas púbicas através de diferentes tipos de medidas e instrumentos que objetivam influenciar o comportamento de diferentes atores e fomentar a qualidade ambiental (STRAUCH, 2008).

Vale lembrar o artigo 225 da Constituição Federal que incumbiu ao poder público, entre outras responsabilidades, a de preservar e restaurar os processos ecológicos essenciais e prover o manejo ecológico das espécies e ecossistemas e controlar a produção, a comercialização e o emprego de técnicas, métodos e substâncias que comportem risco para a vida, a qualidade de vida e o meio ambiente, para a garantia de acesso a todos de um meio ambiente ecologicamente equilibrado, bem de uso comum do povo e essencial à sadia qualidade de vida.

$\mathrm{Na}$ busca de soluções para a promoção das mudanças dos padrões de consumo e produção, o Ministério do Meio Ambiente (MMA) lançou, em 1999, o desafio às instituições governamentais na publicada "Agenda Ambiental na Administração Pública (A3P)", juntamente com vídeo educativo e motivador de novos comportamentos. Em 2004, foi criada a chamada Rede A3P para viabilizar a troca de conhecimentos entre a Administração Pública e assim tornar palpáveis alguns dos conceitos do desenvolvimento sustentável (MMA, 2005).

A A3P é um projeto desenvolvido com o objetivo estimular a adoção de critérios socioambientais na gestão dos órgãos públicos, visando minimizar e ou eliminar os impactos de suas práticas administrativas e operacionais no meio ambiente, por meio da adoção de ações que promovam o uso racional dos recursos naturais e dos bens públicos, além do manejo adequado dos resíduos.

A questão ambiental também está cada vez mais inserida nas atividades relativas ao sistema produtivo e a administração das organizações. Por outro lado, as instituições públicas precisam nortear, regular e administrar o meio ambiente como patrimônio de todos, na busca do desenvolvimento sustentável. Vale lembrar que isso pode começar pelo próprio gerenciamento das repartições públicas através de ações como uso otimizado de recursos e prevenção da poluição, além da abordagem tradicional de atendimento a padrões legais.

O município de São Gonçalo do Amarante localiza-se na Zona do Litoral Oriental do Estado do Rio Grande do Norte, possui uma área territorial de $251 \mathrm{~km}^{2}$, com a altitude de sua 
Sede em 15 metros, e uma população de 86.151 habitantes, configurando-o como o quarto município mais populoso do Estado (IBGE, 2010). Esse município foi criado por meio da lei no 2.323/58, desmembrando-se do município de Macaíba. Atualmente São Gonçalo do Amarante está classificado segundo o Índice de Desenvolvimento Humano (IDH) em 170, apresentando o índice de 0,695 (IBGE, 2010). Do ponto de vista da administração pública, o município possui 12 (doze) secretarias, sendo elas: Secretaria Municipal de Saúde, Tributação, Meio Ambiente e Urbanismo, Educação, Finanças, Agricultura, Infraestrutura, Habitação, Administração, Assistência Social, Serviços Urbanos e Comunicação.

Nessa conjuntura, o presente estudo parte da seguinte questão - problema: Qual a potencialidade de aplicação da A3P nas secretarias de finanças, infraestrutura, saúde e meio ambiente e urbanismo da prefeitura municipal de São Gonçalo do Amarante/RN?

A partir desta indagação, formou-se o objetivo geral como sendo analisar a situação da administração pública para implantação da A3P nas secretarias de finanças, infraestrutura, saúde e meio ambiente e urbanismo do município de São Gonçalo do Amarante/RN. E como objetivos secundários pode-se destacar: conhecer a atual situação da gestão ambiental da esfera pública, e analisar os programas ambientais desenvolvidos nas secretarias municipais de São Gonçalo do Amarante/RN.

Para tanto, o presente estudo foi estruturado em seis capítulos, sendo este, o primeiro, no qual são apresentadas a problemática e os objetivos da pesquisa. Em seguida, na revisão de literatura, os conceitos norteadores são apresentados. No terceiro capítulo descreve-se a metodologia utilizada no presente trabalho. O quarto capítulo apresenta os resultados e discussões obtidos durante a pesquisa e no quinto capítulo, no qual é apresentado as considerações finais do trabalho. Finalmente, no sexto capitulo são apresentadas as referencias utilizadas para fundamentação do trabalho.

\section{REVISÃO DE LITERATURA}

\subsection{Gestão Ambiental}

De acordo com Rohrich e Cunha (2004), a gestão ambiental diz respeito ao conjunto de políticas e práticas administrativas e operacionais que levam em conta a proteção do meio ambiente por meio da eliminação ou mitigação de impactos e danos ambientais decorrentes do planejamento, implantação, operação, ampliação, realocação ou desativação de empreendimentos ou atividades, incluindo-se todas as fases do ciclo de vida do produto. Dessa forma, pode-se dizer que a gestão ambiental envolve as atividades de planejamento e organização do tratamento da variável ambiental pela empresa, objetivando-se alcançar metas ecológicas específicas (SEIFFERT, 2005).

Segundo Barbieri (1997), a solução dos problemas ambientais, ou sua minimização, exige uma nova atitude dos administradores, que devem passar a considerar o meio ambiente em suas decisões e adotar concepções administrativas e tecnológicas que contribuam para ampliar a capacidade do planeta. Isso é motivado na visão de Souza (2002) por fatores como a crescente exigência em relação ao protecionismo ambiental, por parte de organismos 
internacionais; mudanças no cenário mercadológico e frente às descobertas associadas aos danos ambientais.

Assim, para que as instituições públicas passem realmente a trabalhar com gestão ambiental deve, inevitavelmente, passar por mudanças em sua cultura e por uma revisão de paradigmas. Neste sentido, a gestão ambiental tem se configurado com uma das mais importantes atividades relacionadas com o desenvolvimento das atividades de uma repartição. No próximo tópico, serão trabalhadas algumas perspectivas, com destaque a A3P.

\subsection{Gestão Ambiental Pública}

A gestão ambiental no setor público está relacionada ação do poder público conduzido segundo uma política pública ambiental. Através de um o conjunto de objetivos, diretrizes e instrumentos de ação que o poder público dispõe para produzir efeitos desejáveis sobre o meio ambiente (BARBIERI, 1997B).

A Constituição Federal de 1988, ao consagrar o meio ambiente ecologicamente equilibrado como direito de todos, bem de uso comum e essencial à sadia qualidade de vida, atribuiu a responsabilidade de sua preservação e defesa não apenas ao Poder Público, mas também à coletividade. Entretanto, mesmo conferindo à coletividade, também, a obrigação de proteger o meio ambiente, a Constituição de 1988 fez do Poder Público o principal responsável pela garantia, a todos os brasileiros, do direito ao meio ambiente ecologicamente equilibrado.

Para isso, ela origina sete incumbências (que vão desde a preservação e restauração de processos ecológicos até a proteção da fauna e da flora, destacando-se a educação ambiental) ao Poder Público para garantir a efetividade desse direito. Entretanto, o que se vem observando é a intensificação do processo de apropriação e uso dos recursos naturais, não respeitando a capacidade de renovação dos ecossistemas e de forma a não se ter uma qualidade ambiental satisfatória. Na verdade, há interesses e conflitos entre atores sociais, que atuam de alguma forma sobre os meios físico natural e construído, visando ao seu controle ou à sua defesa e proteção (QUINTAS 1992).

O meio ambiente, nos últimos anos, vem sendo exaustivamente discutido em função da degradação da natureza e conseqüente decadência da qualidade de vida, tanto nas cidades, como no campo. Essa situação decorre, entre outras razões, do mau gerenciamento ambiental advindo do setor público e privado (SCHNEIDER, 2001).

A gestão pública sustentável tem como pressuposto básico a utilização de atividades e instrumentos das tecnologias limpas que permitem otimizar as técnicas e os procedimentos de suas operações fabris e de serviços juntamente com suas atividades gerenciais correspondentes. Cabe ainda, o desenvolvimento das atribuições essenciais como o controle e fiscalização do uso dos recursos naturais por diversas atividades produtivas (SHENINI; NASCIMENTO, 2002).

Por outro lado, as atividades da administração pública devem ser encaradas também como potencialmente poluidora, assim a legislação e as normas empregadas para fiscalização 
junto às empresas privadas são as mesmas que devem ser aplicáveis ao serviço público, devendo este adequar-se as demandas. Ou seja, é o papel do Estado como gestor do meio ambiente e em igualdade de condições nas responsabilidades éticas da sustentabilidade.

Assim, na análise da gestão pública sustentável deve-se adicionar os aspectos atitudinais na busca da qualidade total e da boa imagem política e ecologicamente correta que compõem as novas formas de gerir o serviço público (SHENINI; NASCIMENTO, 2002). Nessa conjuntura, vale enfatizar que a gestão ambiental facilita o processo de gerenciamento, proporcionando vários benefícios às repartições públicas. Cagnin (2000) enumera os benefícios da gestão ambiental: redução do consumo de água, energia e outros insumos; reciclagem, venda e aproveitamento e resíduos, e diminuição de efluentes; melhoria da imagem institucional e melhoria nas relações de trabalho.

Contudo, observa-se a responsabilidade das repartições publicas no gerenciamento de seus aspectos ambientais, principalmente o consumo de recursos e o lançamento da diversas formas de poluentes (sólidos, líquidos, gasoso e outras formas de energia). Assim, uma política focada na preservação ambiental pela administração publica que vem ganhando destaque no Brasil é a Agenda Ambiental da Administração Pública, a qual será melhor debatida na próxima seção.

\subsubsection{Agenda Ambiental na Administração Pública}

A Agenda Ambiental na Administração Pública é um programa que visa implantar a responsabilidade socioambiental nas atividades administrativas e operacionais da administração pública. Este programa foi desenvolvido pelo Ministério do meio Ambiente desde 1999, e tem por objetivo estimular a adoção de critérios socioambientais na gestão dos órgãos públicos, com o intuito de minimizar e ou eliminar os impactos de suas práticas administrativas e operacionais no meio ambiente, por meio da adoção de ações que promovam o uso racional dos recursos naturais e dos bens públicos, além do manejo adequado dos resíduos.

A A3P tem como princípios a inserção dos critérios socioambientais nas atividades regimentais, que vão desde uma mudança nos investimentos, compras e contratação de serviços pelo governo até a uma gestão adequada dos resíduos gerados e dos recursos naturais utilizados, além de promover a melhoria na qualidade de vida no ambiente de trabalho (Figura 1). Assim, a A3P tem como diretriz primordial a sensibilização não só dos gestores, mas de todos os colaboradores do serviço público, em todas as suas esferas. É importante ressaltar que o engajamento ao programa é voluntário, restando o desafio individual e coletivo, o desenvolvimento de ações e a construção de atitudes dentro do conceito deste novo modelo de gestão pública. 


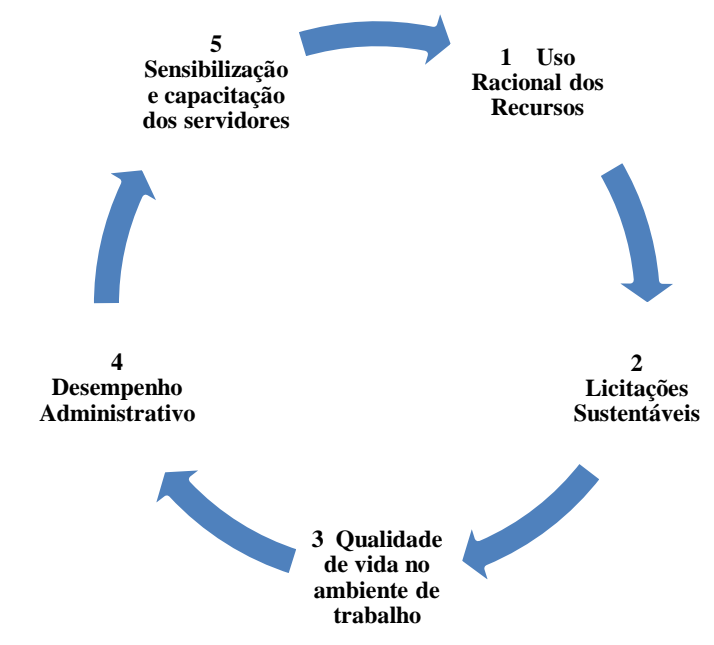

Figura 1: Eixos Temáticos da A3P. Fonte: BRASIL, 2010b.

Contudo observa-se que a A3P busca adequar o comportamento do consumo do Governo aos preceitos constitucionais sobre a responsabilidade ambiental compartilhada, que é tarefa de todos os segmentos da sociedade, do setor público e do produtivo. A implementação da A3P pode trazer uma série de vantagens, tais como: redução de água, energia e outros insumos, estabelecimento de padrões ambientais nas compras de materiais, adoção de programas focados ao ganho de qualidade de vida no ambiente de trabalho para o funcionário, entre outros.

Após da criação da rede A3P para viabilizar a troca de conhecimentos entre os entes da administração pública, bem como com as ações do MMA para consolidar parcerias para implementação da A3P nos entes dos governos estaduais e municipais, observou-se uma ampliação da adesão de entes governamentais. A região Nordeste saiu na frente, firmando parcerias com a Bahia, Pernambuco e Ceará. Com destaque este último, que já está com processo de adesão avançado em 151 de seus municípios, além de doze secretarias estaduais e duas universidades.

\section{METODOLOGIA}

\subsection{Classificação e Delimitação da Pesquisa}

O presente estudo se configura como uma pesquisa exploratória e explicativa, haja vista que não só se embasou em um levantamento bibliográfico relacionado à gestão ambiental e à Administração Pública, como também analisou criticamente os dados obtidos. (SILVA; MENEZES, 2001). No estudo exploratório, buscou-se a definição do problema da pesquisa, efetuação de uma revisão de literatura em livros, periódicos, artigos e sites sobre a aplicação da A3P, além da base conceitual para elaboração do instrumento de coleta de informações. No estudo explicativo, foi desenvolvido através do levantamento de informações através de uma entrevista usando um questionário estruturado com os gestores de quatro secretarias municipais do município de São Gonçalo do Amarante e por fim uma fase analítica, na qual buscou-se uma análise dos dados relevantes, discussão e conclusão (GIL, 1999). 
Desta forma, considerando que o estudo foi aplicado na perspectiva de uma realidade, a Prefeitura de São Gonçalo do Amarante, pode-se considerar também, que este também é classificado como um estudo de caso. Destacam-se alguns exemplos de aplicações desta tipologia de pesquisa: explicar ligações causais em intervenções ou situações da vida real que são complexas demais para tratamento através de estratégias experimentais ou de levantamento de dados; descrever um contexto de vida real no qual uma intervenção ocorreu; avaliar uma intervenção em curso e modificá-la com base em um estudo de caso ilustrativo (YIN, 1994).

Quanto à delimitação da pesquisa, o estudo foi desenvolvido em quatro secretarias da Prefeitura Municipal de São Gonçalo do Amarante/RN, sendo elas: Secretaria Municipal de Meio Ambiente e Urbanismo, Secretaria de Finanças, Secretaria de Infraestrutura e Secretaria de Saúde. Os fatores que motivaram a seleção dessas quatro Secretarias para a realização desse estudo deveram-se tanto ao nível de relevância dos programas destas para a sociedade quanto à facilidade de acesso aos seus gestores.

A Secretaria Municipal de Meio Ambiente e Urbanismo de São Gonçalo do Amarante/RN tem como função realizar as atividades de análise, controle, fiscalização do uso, parcelamento do solo e da poluição e degradação ambiental, no Município, em especial quanto às obras e edificações.

A Secretaria Municipal de Finanças, por sua vez, tem como função, administrar tudo que se refere ao movimento financeiro da Prefeitura, o que envolve dotação orçamentária, recebimentos, pagamentos, bem como o cumprimento da Lei de Responsabilidade Fiscal (Lei Complementar 101), Lei de Licitações (Lei 8.666), Lei de Diretrizes Orçamentárias, entre outras, assegurando que o dinheiro público seja usado de forma correta, útil e responsável.

Já a Secretaria Municipal de Infraestrutura tem como função acompanhar as obras do Governo, desde sua concepção até a conclusão das mesmas, reunindo sobre elas todas as informações acerca de seu andamento e controlando os prazos de execução de cada etapa.

Por fim, a Secretaria Municipal de Saúde de São Gonçalo do Amarante/RN tem como função promover medidas de prevenção e proteção à saúde da população do município, mediante o controle e o combate de morbidades físicas, de doenças infecto-contagiosas, de déficits nutricionais da população e de problemas mentais.

\subsection{Descrição do Processo de Coleta de Informação}

A coleta de informações foi efetuada no mês de novembro de 2010, através de uma entrevista com os gestores das secretarias já mencionadas. A entrevista foi orientada através de um questionário padronizado e estruturado em questões abertas e fechadas, a entrevista abordou os seguintes eixos temáticos estabelecidos pela A3P (Cf. Figura 1): uso racional dos recursos, licitação sustentável, qualidade de vida no ambiente de trabalho, desempenho administrativo, sensibilização e capacitação dos servidores. 
Esses eixos temáticos formaram os grupos de variáveis analíticas para investigação das potencialidades de aplicação da A3P, a fim de inserir a variável ambiental nas atividades administrativas e operacionais das secretarias. (Cf. Figura 2).

O primeiro grupo de variáveis analíticas, uso racional de recursos, teve como objetivo analisar a conduta das secretarias frente ao gerenciamento de alguns aspectos ambientais, para se evitar impactos no meio ambiente (ABNT, 2004), tais como o consumo de materiais (Uso racional - UR-MAT1 e preferência por fornecedores com Licença Ambiental - UR-MAT2), o consumo de água (Uso racional - UR-AGUA1 e controle de qualidade no uso - UR-AGUA2) e o consumo de energia (Uso racional - UR-ENER1 e utilização de outra fonte - UR-ENER2), além do gerenciamento de resíduos sólidos (Separação dos resíduos - UR-RS1; área de armazenamento - UR-RS2; destinação final adequada dos resíduos gerados pelas secretarias UR-RS3).

A seguir, destaca-se o grupo de variáveis licitações sustentáveis que tem por objetivo verificar a existência de algumas práticas ambientais no processo licitatório, no caso, a exigência de selos ambientais (LS-SELO) e solicitação de materiais recicláveis (LS-RECICLA). Os selos ambientais são informações objetivas, relevantes e compreensíveis, facilitando, assim, a comunicação e a linguagem ambiental para que o consumidor entenda e se familiarize com as questões ambientais (KOHLRAUSCH, 2004). A título de exemplificação, tem-se o selo Procel relacionado à eficiência energética de equipamentos elétricos.

Já o grupo qualidade de vida no ambiente do trabalho contemplou as seguintes variáveis: QVT-1 (Programa de Qualidade de Vida no Trabalho), QVT-2 (Programa de Reconhecimento e Mérito, assegurado a diferenciação e valorização do desempenho profissional), QVT-3 (Equipamentos de proteção coletiva), QVT-4 (Adequação do espaço físico interno do ambiente de trabalho acusticamente), QVT-5 (Comunicação eficaz entre as hierarquias) e QVT-6 (Objetivos individuais e de equipe).

O grupo de desempenho administrativo, por sua vez, contemplou as seguintes variáveis: DA-1 (Programa de Aplicação Periódica de Avaliação do Desempenho Institucional), DA-2 (Programa de Elaboração do Plano de Atividades), DA-3 (Programa de Gerenciamento do Orçamento), DA-4 (Programa de Cumprimento do Plano de Atividades e Orçamento), DA-5 (Programa de Informatização ou Gerenciamento Eficaz na Área de Secretariado), DA-6 (Definição de objetivos em acordo com os planos e atividades elaborados no PPA), DA-7 (Programas que fixam os objetivos do serviço para o ano seguinte) e DA-8 (Relatório anual da avaliação do desempenho).

Por fim, o grupo de variáveis sensibilização e capacitação dos servidores apresentou as seguintes variáveis: SCS-1 (Programa de Capacitação de Servidores na Secretaria) e SCS-2 (Programa Interno de Conscientização para Funcionários e Usuários dos Serviços).

No questionário, a escala de resposta das questões fechadas adotada foi: Não Implementado, Às vezes, Em Implementação e Implementado. Desta forma, buscou-se analisar o nível de maturidade das ações desenvolvidas pelas secretarias de forma a analisar a potencialidade de aplicação da A3P. 


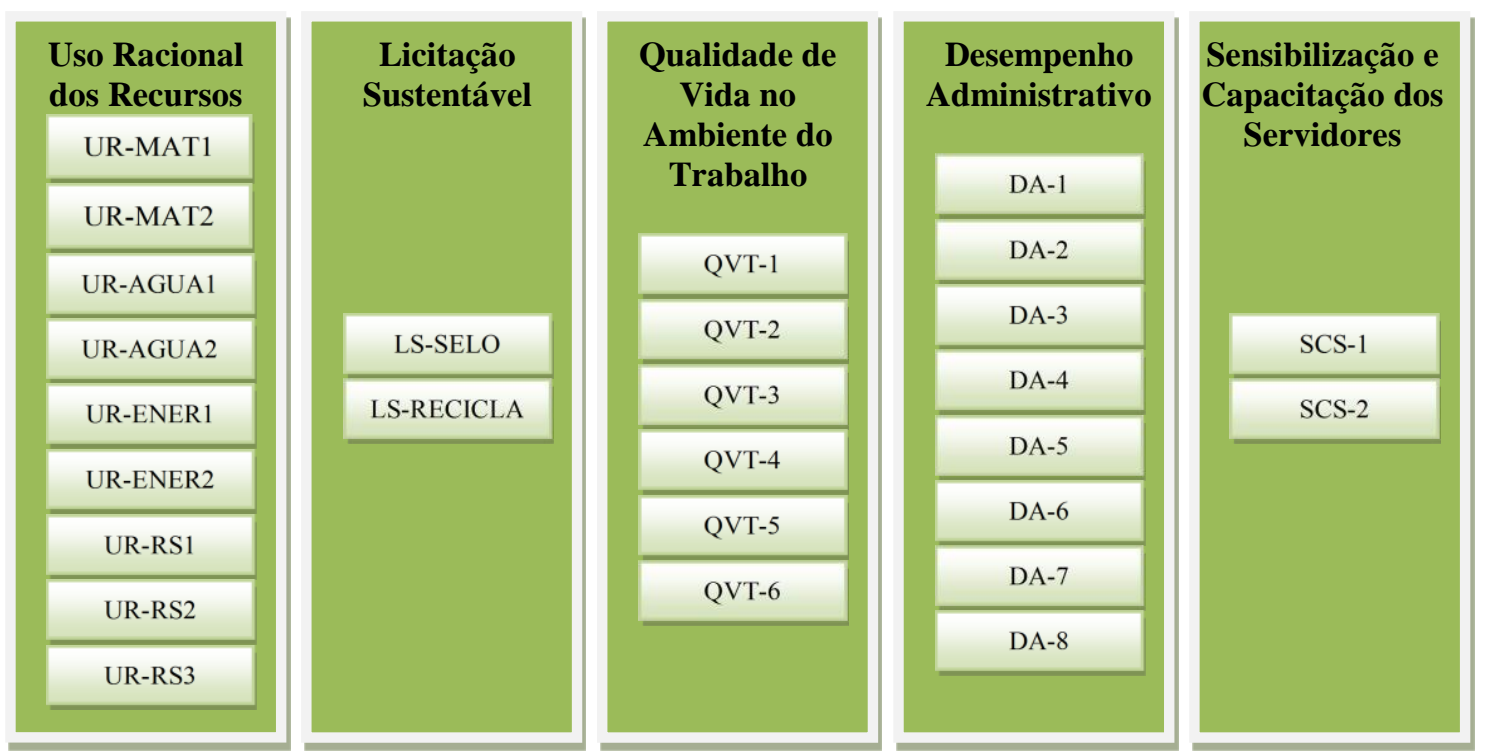

Figura 2: Variáveis analisadas na pesquisa de campo.

\section{RESULTADOS E DISCUSSÕES}

\subsection{Uso racional dos recursos}

\subsubsection{Material}

Em relação ao consumo de material (UR-MAT1), foi constatado que as secretarias estudadas não possuíam procedimentos formais de controle do uso de materiais, apenas, às vezes, elas implementam algumas ações. (Cf. Figura 3).

Figura 3: Uso racional de recursos - Materiais.

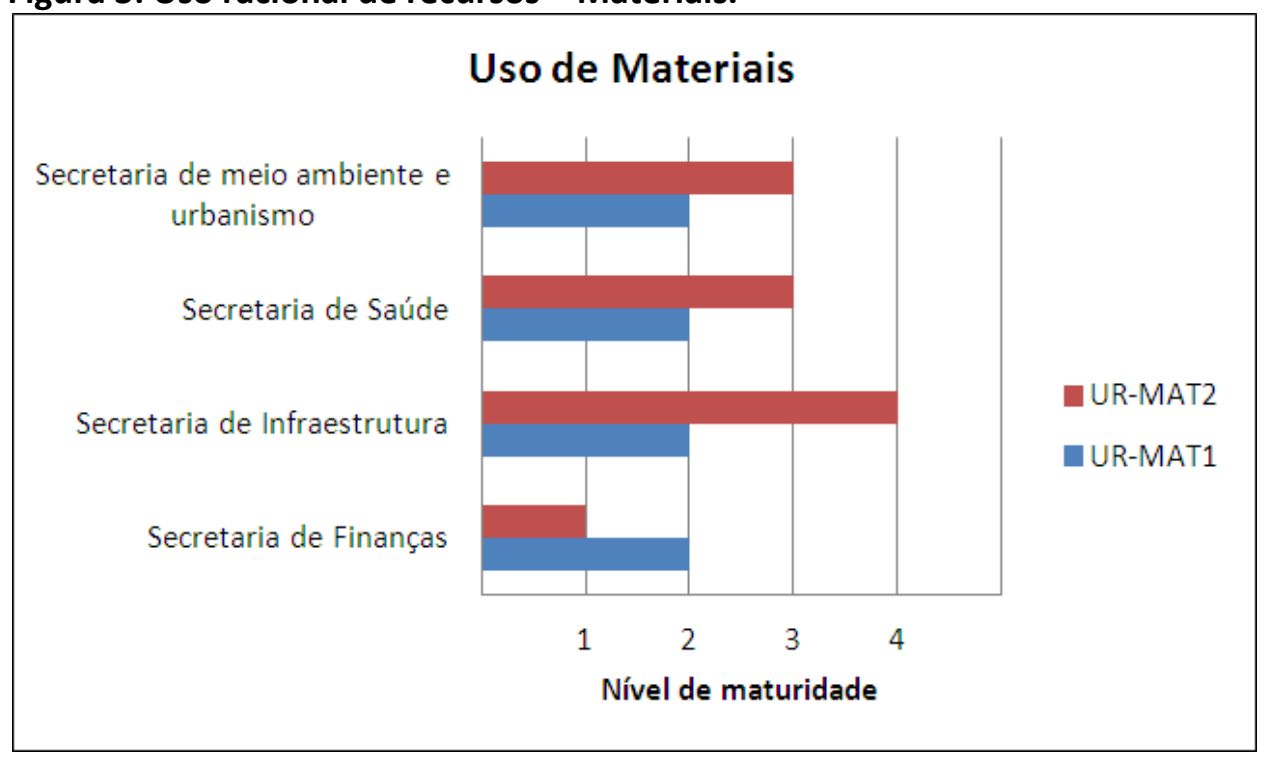

HOLOS, Ano 27, Vol 4 
Onde: 1 - Não, 2 - Às vezes, 3 - Em implementação e 4-Implementado.

Fonte: pesquisa de campo, 2010.

Por outro lado, vale destacar uma conduta positiva quanto à preferência por fornecedores com licença ambiental (UR-MAT2), já que uma secretaria havia implementado procedimentos para dar preferência a fornecedores com licença ambiental (Infraestrutura) e outras duas, Secretaria de Meio Ambiente e Urbanismo e a Secretaria de Saúde, estavam em processo de implantação de procedimentos. (Cf. Figura 3).

Vale enfatizar, ainda, que a Secretaria de Finanças apresentou uma conduta negativa em relação à UR-MAT2, já que esta não prioriza fornecedores com um nível mínimo de adequação ambiental.

É oportuno lembrar que a posse, o atendimento dos requisitos e a contínua renovação da licença ambiental são garantias mínimas cuja atividade controla sua influencia sob o meio ambiente, já que esta consiste no ato administrativo pelo qual o órgão ambiental competente, estabelece as condições, restrições e medidas de controle ambiental durante a operação de uma dada atividade poluidora. (BRASIL, 1997). Desta forma, ao adotar como critério a posse da licença ambiental na seleção de fornecedores, a secretaria cria um mecanismo positivo em favor da redução dos impactos ambientais.

\subsection{2 Água}

No que se refere ao uso racional da água (UR-AGUA1), apenas uma secretaria está em processo de implantação de procedimentos para um uso mais coerente (Infraestrutura), através de orientações aos seus funcionários sobre o desperdício de água. (Cf. Figura 4).

No controle de qualidade do uso da água (UR-AGUA2), a Secretaria de Meio Ambiente e Urbanismo chama a atenção pela contradição existente na política de controle de água, isto é, seus resultados obtidos junto à população sãogonçalense são satisfatoriamente compatíveis com o exigido pela A3P, porém não há o controle da qualidade da água usada nos setores desta secretaria. Por outro lado, merece destaque a Secretaria de Saúde que possui, em fase de implementação, o Programa Vigiágua. (Cf. Figura 4).

Figura 4: Uso racional de recursos - Água. 


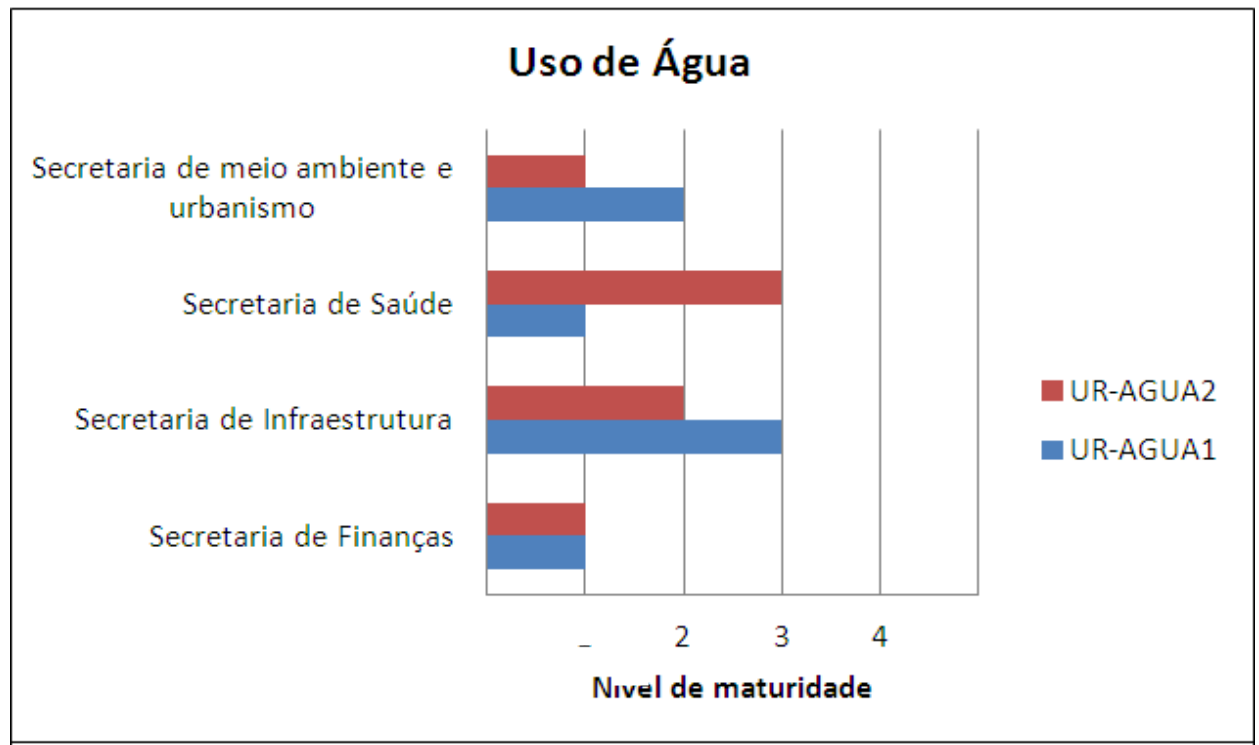

Onde: 1 - Não, 2 - Às vezes, 3 - Em implementação e 4-Implementado.

Fonte: pesquisa de campo, 2010.

\subsubsection{Energia}

Com relação ao uso racional de energia elétrica (UR-ENER1), três secretarias (Secretaria do Meio Ambiente e Urbanismo; Secretaria de Saúde; Secretaria de Infraestrutura) estão em implementação de procedimentos para uso otimizado desse recurso. A ação pauta-se na instalação de lâmpadas mais econômicas e calhas luminosa. (Cf. Figura 5).

Figura 5: Uso racional de recursos - Energia.

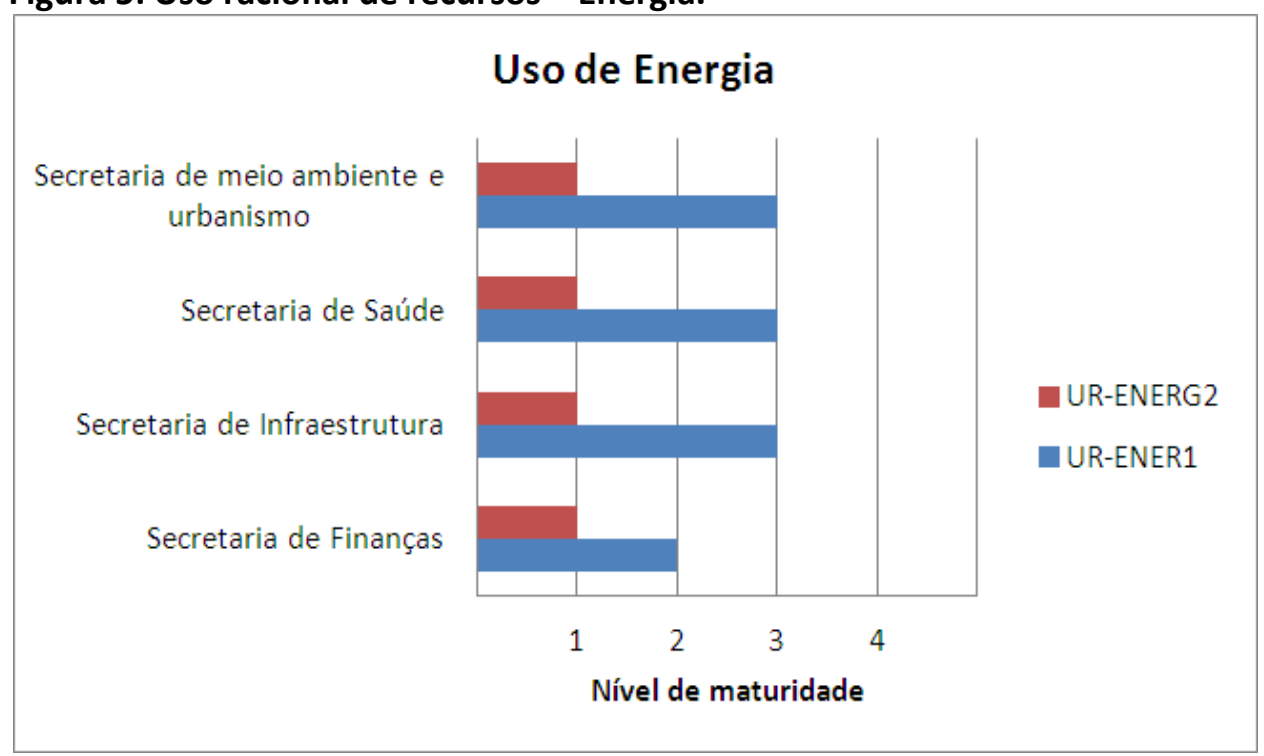

Onde: 1 - Não, 2 - Às vezes, 3 -Em implementação e 4 -Implementado.

Fonte: pesquisa de campo, 2010.

Já a Secretaria de Finanças não possuía procedimentos formais de controle, já que, às vezes, tenta otimizar o uso energético. Por fim, quanto ao uso de outras fontes de energia (URENER2), nenhuma das Secretarias estudadas faz uso de outra fonte, apenas o da energia fornecida pela Rede pública. (Cf. Figura 5). 


\subsubsection{Resíduos}

Em relação aos resíduos sólidos, foi efetuada uma análise a respeito dos elementos do gerenciamento destes. Para tanto, considerou-se que o gerenciamento de resíduos deve ser sistematizado através de um plano de gerenciamento de resíduos sólidos, entendido como um processo que aponta e descreve as ações relativas ao manejo dos resíduos sólidos no âmbito dos estabelecimentos, contemplando a segregação na origem, coleta, manipulação, acondicionamento, armazenamento, transporte, minimização, reutilização, reciclagem, tratamento e disposição final. (PIMENTA; MARQUES JUNIOR, 2006).

Desta forma, os elementos analisados nas secretarias estudadas foram: a existência de procedimentos de separação dos resíduos - UR-RS1; a existência de área de armazenamento - UR-RS2; e a existência de procedimentos de destinação final adequada dos resíduos - URRS3. (Cf. Figura 6).

É relevante, ainda, destacar que a separação de resíduos na fonte consiste em um procedimento de segregação, de acordo com a classificação dos resíduos no local ou a etapa onde foi gerado. Já a área de armazenamento incide em um depósito dos resíduos nos recipientes designados e apropriados para cada tipologia/classificação, conforme suas características e possibilidade de reaproveitamento, tratamento ou destino para reciclagem (MACEDO; GOUVINHAS; PIMENTA, 2008). Por fim, a destinação final, que, de acordo com a Política Nacional de Resíduos Sólidos - PNRS, por meio de alternativas, busca evitar danos ou riscos à saúde pública e à segurança; e minimizar os impactos ambientais adversos com a reutilização, a reciclagem, a compostagem, a recuperação e o aproveitamento energético e outras destinações admitidas pelos órgãos competentes. (BRASIL, 2010a).

Em relação à Secretaria de Meio Ambiente e Urbanismo de que se espera uma melhor conduta ambiental, foi constatado que não há procedimentos estruturados para o gerenciamento de resíduos, já que não há uma área de armazenamento e apenas, "às vezes", a secretaria efetua segregação na fonte e destina corretamente.

A Secretaria de Infraestrutura também não possuía uma área de armazenamento, às vezes, fazia a separação na fonte. No momento em que ocorreu a entrevista para esse estudo, ela estava em processo de implantação de procedimentos de destinação final adequado dos resíduos.

A seguir, mais uma vez, a Secretaria de Finanças apresentou um desempenho não satisfatório, já que não praticava a segregação na fonte dos resíduos, e apenas, às vezes, fazia uma destinação adequada desses resíduos.

Por fim, a Secretaria de Saúde apresentou um melhor desempenho, apresentando procedimentos para implementação de segregação dos resíduos na fonte e com procedimentos de destinação final dos resíduos implementados. Todavia, a Secretaria não possuía uma área de armazenamento. 
Figura 6: Uso racional dos recursos - Gerenciamento de Resíduos Sólidos.

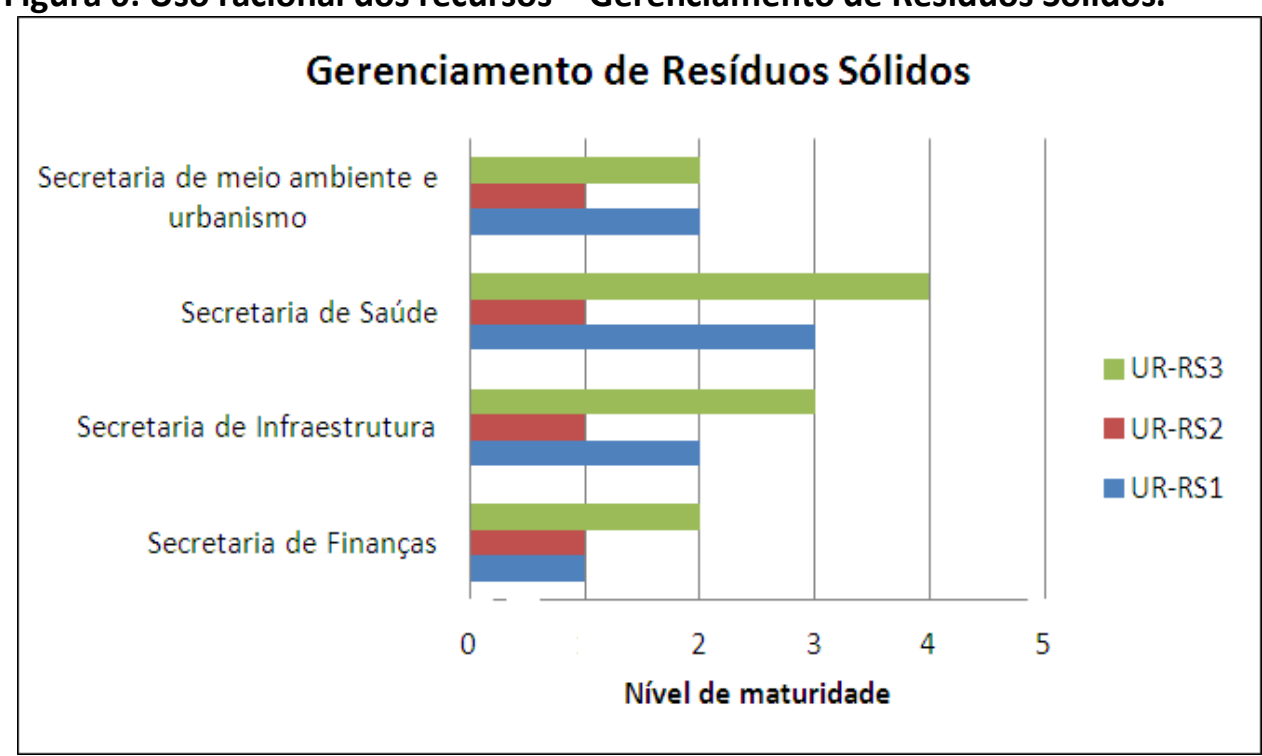

Onde: 1 - Não, 2 - Às vezes, 3 - Em implementação e 4 - Implementado.

Fonte: pesquisa de campo, 2010.

\subsection{Licitação Sustentável (LS)}

Quanto às variáveis "exigência de selos ambientais" (LS-SELO) e "solicitação de materiais recicláveis" (LS-RECICLA), componentes do grupo Licitações Sustentáveis, a Secretaria de Finanças obteve, mais uma vez, o pior desempenho em relação à variável LSSELO. Diferentemente, em suas licitações, as outras secretarias estão em processo de implantação da exigência de produtos com o selo ambiental, como por exemplo, PROCEL.

Já em relação à exigência da aquisição de materiais recicláveis na licitação (LS-RECICLA), não há um processo formalizado já que todas as secretarias efetuam apenas, "às vezes", essa prática. (Cf. Figura 7).

Figura 7: Licitação Sustentável. 


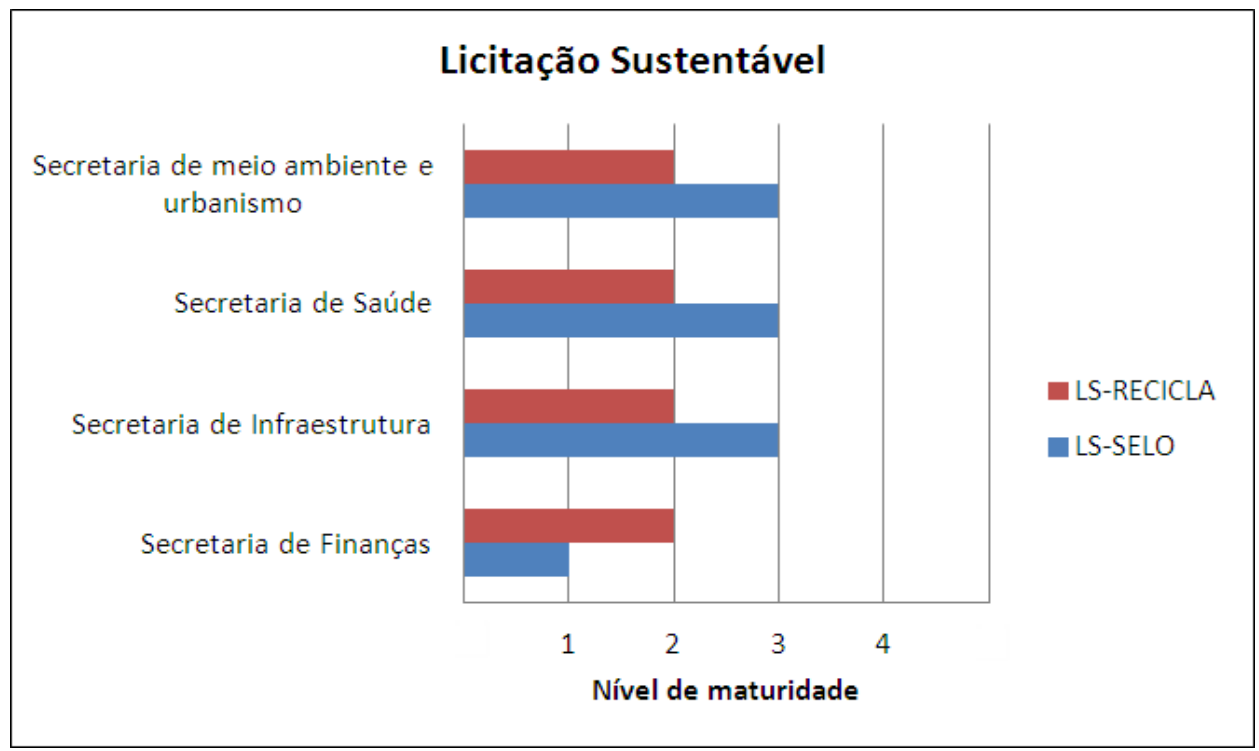

Onde: 1 - Não, 2 - Às vezes, 3 - Em implementação e 4 - Implementado.

Fonte: pesquisa de campo, 2010.

\subsection{Qualidade de Vida no Ambiente de Trabalho (QVT)}

Em relação à existência de Programas de Qualidade de Vida no Trabalho (QVT-1), a Secretaria de Saúde encontra-se em processo de implantação. Por outro lado, as demais secretarias não possuem algum programa implementado. (Cf. Figura 8).

A Secretaria de Saúde também se encontra em processo de implantação de um programa de reconhecimento e mérito, assegurando a diferenciação e valorização do desempenho profissional (QVT-2), enquanto que as demais secretarias não possuem programas ou procedimentos formalizados neste item. (Cf. Figura 8).

Quanto ao uso de equipamentos de proteção (QVT-3), a Secretaria de Saúde possui um programa implantado; já a Secretaria de Infraestrutura está em implantação. Enfatiza-se que estas secretarias são as que possuem riscos mais representativos para os trabalhadores, por isso o uso de equipamentos de proteção é um mecanismo obrigatório que pode evitar maiores lesões aos trabalhadores em situações de risco efetivo. (Cf. Figura 8).

Com relação à adequação do espaço físico interno do ambiente de trabalho, especificamente no que tange à acústica (QVT-4), a Secretaria de Saúde possui programas implementados, enquanto que as demais não possuem programas formalizados. Destaca-se que esta variável possui uma influência direta no bom desempenho dos funcionários. (Cf. Figura 9).

A existência de uma comunicação eficaz entre as hierarquias (QVT-5) foi relatada pelas Secretarias de Saúde e de Infraestrutura. Nas demais, não há procedimentos formais implementados, ocorrendo frequentemente falhas no processo de comunicação. (Cf. Figura 9). 
Finalmente, em relação à existência de objetivos individuais e de equipe (QVT-6), a Secretaria de Saúde era a única com procedimentos formais implementados. (Cf. Figura 9).

Figura 8: Qualiadde de vida no ambiente de trabalho (Variáveis - QVT1, QVT2 e QVT3).

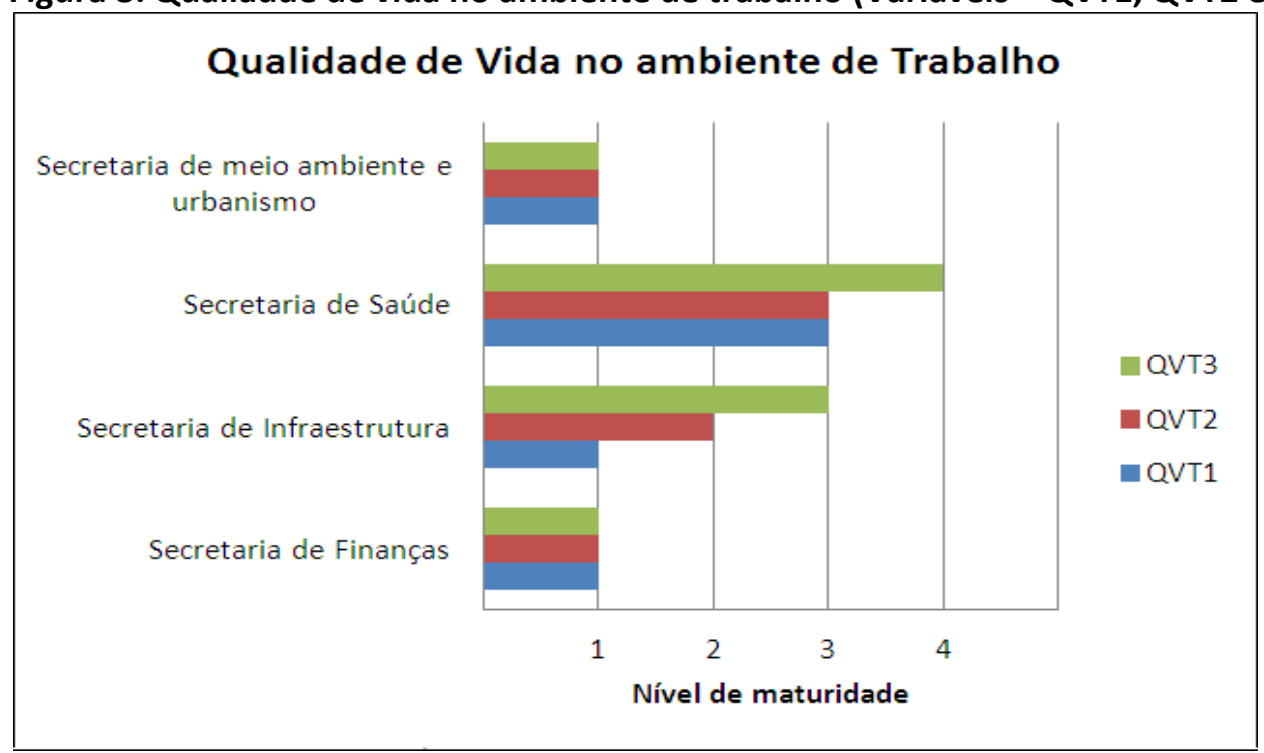

Onde: 1 - Não, 2 - Às vezes, 3 - Em implementação e 4 -Implementado.

Fonte: pesquisa de campo, 2010.

Figura 9: Qualiadde de vida no ambiente de trabalho (Variáveis - QVT4, QVT5 e QVT6).

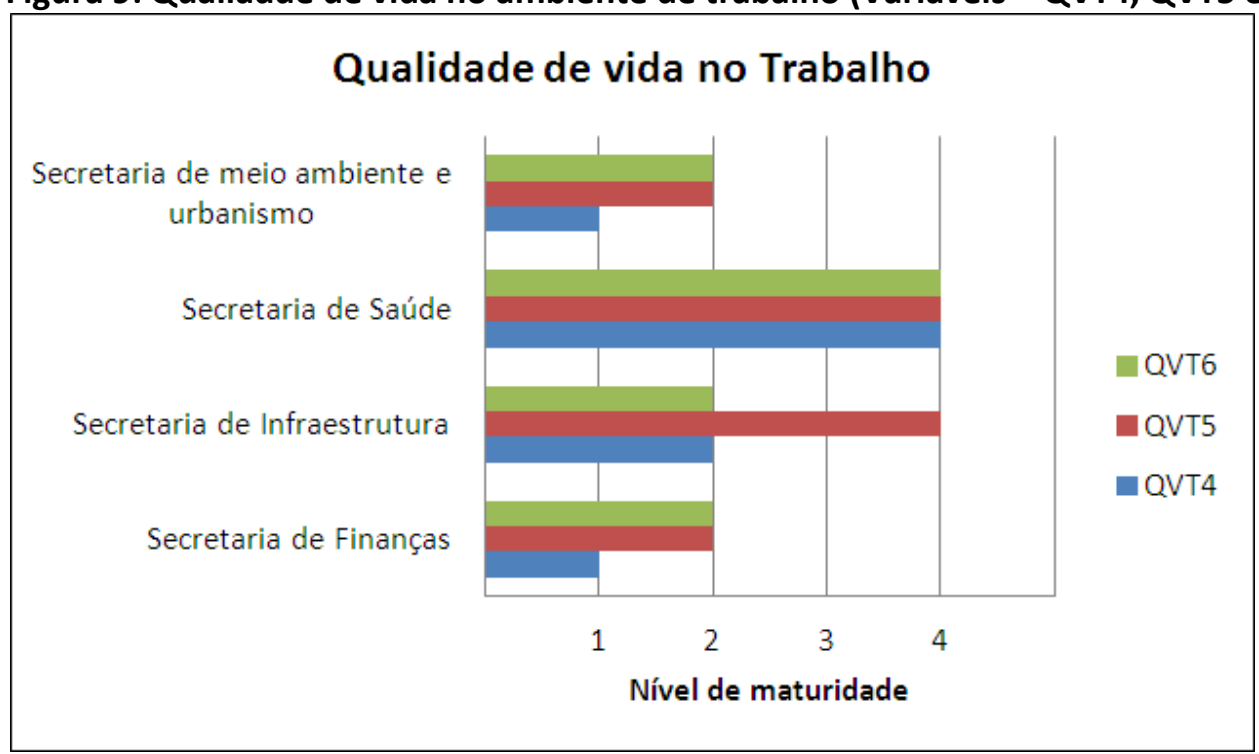

Onde: 1 - Não, 2 - Às vezes, 3 - Em implementação e 4-Implementado.

Fonte: pesquisa de campo, 2010.

\subsection{Desempenho Administrativo (DA)}

Os resultados apresentados pelas secretarias no desempenho administrativo mostraram que a Secretaria de Saúde está implementado todas as variáveis deste grupo. Esse resultado vem mostrar o bom desempenho desta Secretaria no município. As demais estão 
em processo de implementação ou já tem implementadas as variáveis estudadas neste grupo. (Cf. Figuras 10 e 11).

Figura 10: Desempenho Administrativo (Variáveis - DA1, DA2, DA3 e DA4).

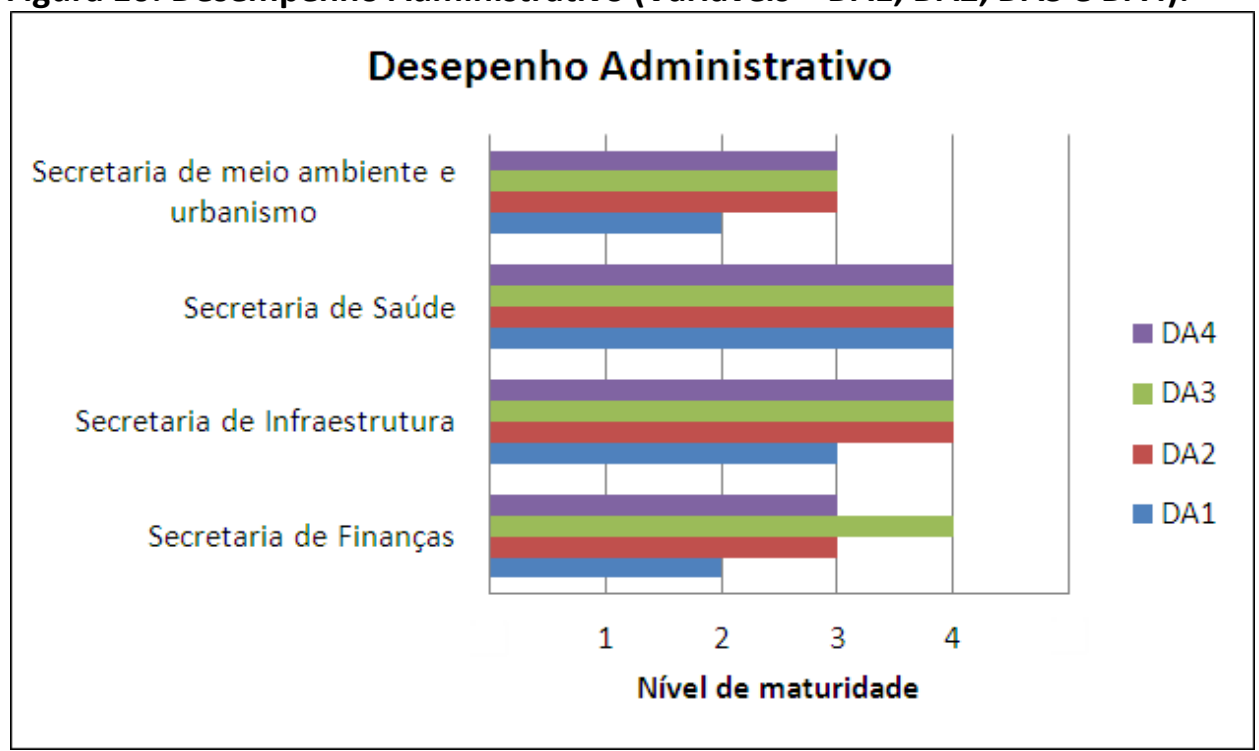

Onde: 1 - Não, 2 - Às vezes, 3 - Em implementação e 4 -Implementado. Fonte: pesquisa de campo, 2010.

Figura 11: Desempenho Administrativo (Variáveis - DA5, DA6, DA7 e DA8).

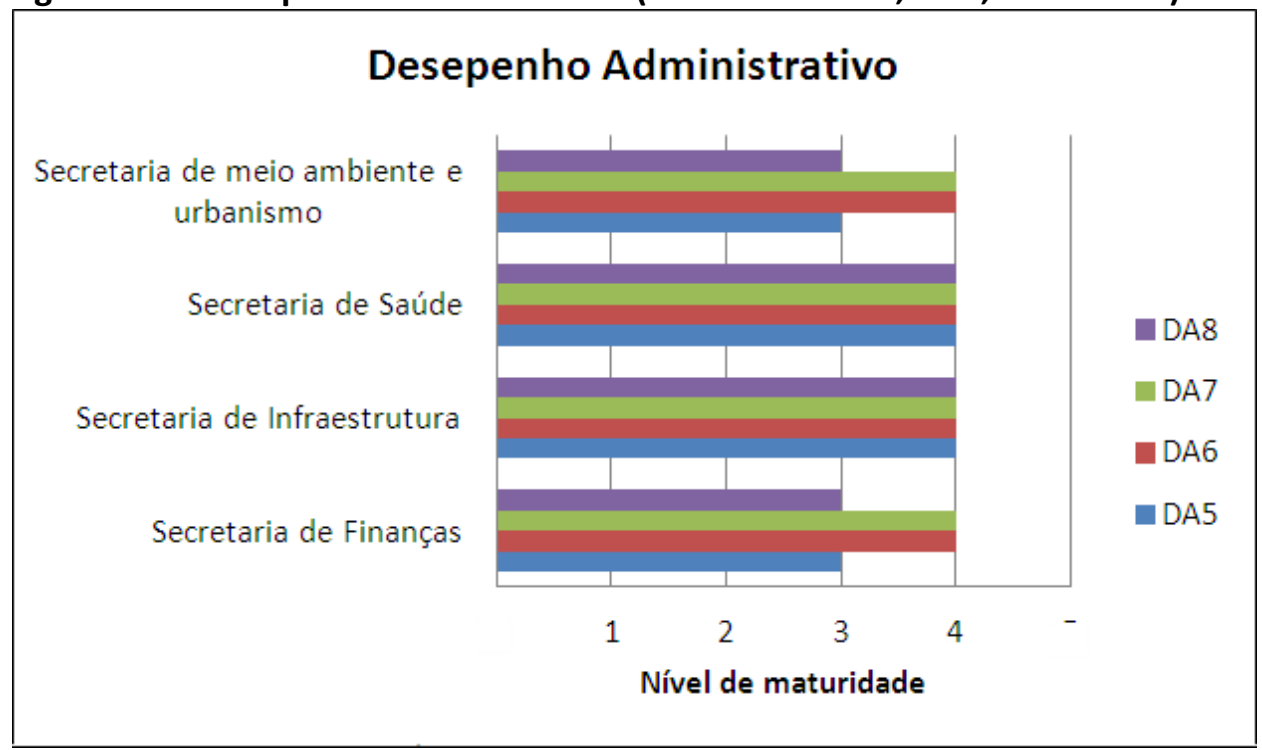

Onde: 1 - Não, 2 - Às vezes, 3 - Em implementação e 4 -Implementado.

Fonte: pesquisa de campo, 2010.

\subsection{Sensibilização e capacitação dos servidores (SCS)}


Em relação à existência de um Programa de Capacitação de Servidores na Secretaria (SCS-1), apenas a Secretaria de Saúde está em processo de implantação; as demais não possuem um programa sistematizado. (Cf. Figura 12).

Em suma, quanto à existência de um Programa Interno de Conscientização para Funcionários e Usuários dos Serviços (SCS-2), a Secretaria de Finanças possui um programa implementado; a Secretaria de Saúde, por sua vez, está em processo de Implantação; já as demais não possuem uma rotina de capacitação sistematizada, somente, "às vezes", efetuam ações. (Cf. Figura 12).

Figura 12: Sensibilização e capacitação dos servidores.

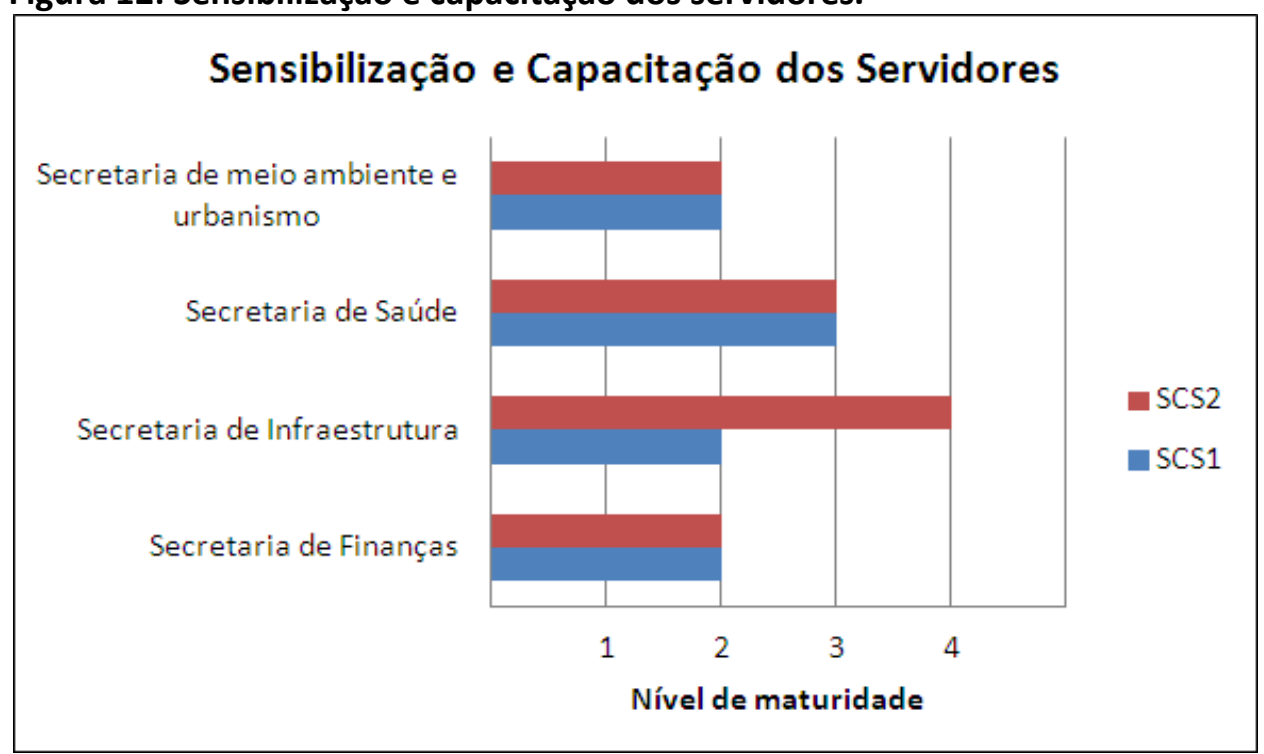

Onde: 1 - Não, 2 - Às vezes, 3 - Em implementação e 4 - Implementado.

Fonte: pesquisa de campo, 2010.

\subsection{Análise da potencialidade da aplicação da A3P}

Considerando os resultados, observa-se que, em relação ao gerenciamento preventivo, através do uso racional de recursos naturais, tais como água e energia, as secretarias analisadas, de uma forma geral, apresentam uma conduta positiva apenas para o uso racional de energia, já que as secretarias de Meio Ambiente e Urbanismo, Saúde e Infraestrutura estão em procedimentos de implantação. Todavia, nenhuma delas possui outra fonte de energia, além da fornecida pela Companhia Energética do Rio Grande do Norte - COSERN.

No que diz respeito ao consumo de água, apenas a Secretaria de Infraestrutura estava em processo de implantação de procedimentos. Quanto ao uso de materiais, nenhuma das secretarias apresentava procedimentos para racionalização do uso. Assim, observa-se um ponto potencial para desenvolvimento de ações de gestão ambiental, através do estabelecimento de rotinas que venham otimizar o uso de recursos como água, energia e materiais, juntamente com ações de educação ambiental com os colaboradores e gestores destas secretarias em análise. 
Quanto ao gerenciamento de resíduos sólidos, foi constatado que nenhuma secretaria possuía área de armazenamento dos resíduos gerados. Isso pode potencializar a contaminação do meio ambiente, dependendo do volume de resíduos gerado, da área de disposição temporária. No desenvolvimento dessa temática nas secretarias, recomenda-se que o gerenciamento adotado atenda às exigências da PNRS, a qual, por exemplo, apresenta como ordem sequencial do gerenciamento dos resíduos a não geração, a redução, a reutilização, a reciclagem, o tratamento dos resíduos sólidos e a disposição final ambientalmente adequada dos rejeitos. (BRASIL, 2010a).

Do ponto de vista das licitações sustentáveis, foi observada uma conduta positiva quanto à exigência da licença ambiental (UR-MAT2 - Embora pela metodologia da A3P essa variável não esteja dentro do grupo licitações sustentáveis, trata-se de um elemento com total relação com o grupo) das empresas participantes, bem como de selos ambientais de produtos eletroeletrônicos, por exemplo. Todavia, faz-se necessário um amadurecimento do uso de materiais recicláveis pelas secretarias, por exemplo, o estabelecimento de um programa para o uso de papel A4 reciclável, um material de elevada demanda.

Quanto ao grupo qualidade de vida, a Secretaria de Saúde demonstrou um bom desempenho em todas as variáveis analisadas, já que estava em processo de implantação ou já tinha implementado algum dos programas. Por outro lado, no que tange às variáveis desse grupo, programas de qualidade de vida, programas de reconhecimento e mérito, uso de equipamentos de proteção, adequação do espaço físico interno, comunicação eficaz entre as hierarquias e a existência de objetivos individuais e de equipe, as demais secretarias não possuíam programas/procedimento/rotinas devidamente implementados, ou seja, quando, de fato, não possuíam, só efetuavam ações isoladas esporadicamente.

Assim, nota-se que, do ponto de vista das práticas voltadas para a qualidade de vida dos colaboradores, não foi observado um comprometimento dos gestores com os colaboradores nas Secretarias de Meio Ambiente e Urbanismos, Infraestrutura e Finanças. Nota-se que, desenvolver atividades/serviços ao mesmo tempo em que se busca melhorar a qualidade de vida da força do trabalho, são características que definem a responsabilidade social (HOLME; WATTS, 2000). Em adição a essa idéia, vale lembrar que a responsabilidade social corporativa pode ser trabalhada em cima de duas abordagens: a interna e a externa, independente do porte e da tipologia empresarial (ASHLEY, 2003; PRIMOLAN, 2004). Como foco deste trabalho, e considerando as variáveis deste grupo, logo nota-se que tais variáveis estão diretamente inseridas nas características da responsabilidade social interna, a qual começa pela valorização profissional e a melhoria da qualidade de vida dos funcionários e, em uma perspectiva mais ampla, de suas famílias. As empresas devem desenvolver algumas ações visando definir seu legado corporativo, instalando uma ética de educação e de aprendizado na organização e instituindo processos que fomentem esse traço cultural.

Quanto ao grupo desempenho administrativo, observou-se um bom desempenho nas variáveis analisadas por todas as secretarias, já que estas se encontravam implementadas ou em processo de implantação. 
Quanto ao grupo de sensibilização e capacitação dos servidores também associado com a temática responsabilidade social interna, as secretarias de Saúde e de Infraestrutura, apresentaram um desempenho um pouco melhor se comparadas as demais que estavam em processo de implantação ou tinham implementado as variáveis deste grupo. As demais não tinham procedimentos devidamente implementados.

Desta forma, não só as variáveis do grupo uso racional dos recursos como também a variável solicitação de materiais recicláveis (LS-RECICLA) precisam ser melhor trabalhadas em todas as secretarias estudadas. Ressalte-se, finalmente, as variáveis do grupo qualidade de vida no ambiente do trabalho que também precisam ser melhor abordada nas secretarias, com exceção da Secretaria de Saúde que demonstrou um bom desempenho.

\section{CONSIDERAÇÕES FINAIS}

Abordou-se a temática da gestão ambiental em repartições públicas, através de um estudo sobre a potencialidade de aplicação da ferramenta A3P nas Secretarias de Finanças, de Infraestrutura, de Saúde e Meio Ambiente e Urbanismo da Prefeitura Municipal de São Gonçalo do Amarante/RN. A A3P consiste em um programa que visa implantar práticas de gestão ambiental e responsabilidade social nas atividades administrativas e operacionais da Administração Pública.

Desta forma, ficou constatado que os grupos com maior potencialidade de desenvolvimento de trabalhos foram: Uso racional de recursos; Licitações sustentáveis; Qualidade de Vida e Sensibilização e Capacitação dos Servidores. Em relação ao uso de racional de recursos, destaca-se uma potencialidade de trabalhar quanto ao uso racional da água, uso de materiais e gerenciamento de resíduos. Em relação às licitações sustentáveis, a maior potencialidade está no fato de se comprar materiais de consumo recicláveis, como papel, o que não é feito. Por fim, programas de sensibilização e capacitação devem ser implementados e mantidos, de acordo com as demandas e serviços prestados pelas secretarias.

Enfatiza-se que o baixo desempenho em relação ao uso preventivo de recursos naturais, como materiais, água e energia, além do gerenciamento inadequado dos resíduos, denota uma conduta falha em relação ao controle dos aspectos ambientais que podem causar impactos sobre o meio ambiente. Sobretudo, a Secretaria de Meio Ambiente e Urbanismo que poderia demonstrar um bom desempenho, principalmente por demandar essa boa conduta das atividades efetiva ou potencialmente poluidoras no processo de licenciamento ambiental.

De forma geral, as secretarias com um melhor desempenho em relação à potencialidade de aplicação da A3P foram as Secretarias de Saúde e a de Infraestrutura. Acredita-se que isso se deve à percepção dos gestores entrevistados sobre a sustentabilidade. Por outro lado, constatou-se que os gestores das Secretarias de Finanças e Meio Ambiente e Urbanismo eram conscientes da importância da implantação da $\mathrm{A} 3 \mathrm{P}$, porém não tinham o interesse em desenvolver, naquele momento, as variáveis avaliadas. 
Destaca-se que, para o processo de mudança, principalmente de hábitos e costumes do dia a dia, não basta fazer, e sim saber fazer, ou seja, para implementar a A3P nas secretarias é preciso um planejamento baseado na participação social dos agentes envolvidos, formulando, implementando e avaliando políticas ambientais com base na cultura, realidade e potencialidades de cada secretaria, em conformidade com os princípios de desenvolvimento sustentável.

Assim, com este estudo, pretende-se instaurar um processo de construção de uma nova cultura institucional no município de São Gonçalo do Amarante/RN, visando à introdução de técnicas de educação ambiental que almejem a conscientização dos servidores para a otimização dos recursos no combate ao desperdício e para a busca de uma melhor qualidade do ambiente de trabalho. Poderá ser adotado como foco inicial, o trabalho das secretarias cujas variáveis apresentaram os piores desempenhos nesta análise, a fim de que busquem o apoio necessário nos órgãos superiores, com suporte do Ministério do Meio Ambiente e da Comissão Gestora da A3P.

\section{REFERÊNCIAS BIBLIOGRÁFICAS}

1. ASSOCIAÇÃO BRASILEIRA DE NORMAS TÉCNICAS - ABNT. ABNT NBR ISO 14001:2004 Sistema de gestão ambiental: requisitos com orientações para uso. Rio de Janeiro: ABNT, 2004.

2. ASHLEY, Patrícia Almeida (Org.). Ética e responsabilidade social nos negócios. São Paulo: Saraiva, 2003. 205 p.

3. BARBIERI, J. C. Desenvolvimento e Meio Ambiente: As Estratégias de Mudança da Agenda 21. Petrópolis, RJ: Vozes, 1997.

4. B. J. C. Políticas públicas indutoras de inovações tecnológicas ambientalmente saudáveis. Rio de Janeiro, Revista de Administração Pública v.31 (2), mar - abr 1997.

5. BRASIL. Constituição Federal, 1998. Disponível em: < www.planalto.gov.br/ccivil 03/.../constituiçao.htm>. Acesso em: 14 mar. 2011.

6. Lei $\mathbf{n}^{\circ}$ 12.305, de 02 de agosto de 2010. Institui a Política Nacional de Resíduos Sólidos; altera a Lei nº 9.605, de 12 de fevereiro de 1998; e dá outras providências. Disponível em: <http://www.mma.gov.br/>. Acesso em: 05 set. 2010a.

7. _. Ministério do Meio Ambiente. A3P - Agenda Ambiental na Administração Pública. Disponível em: <www.mma.gov.br>. Acesso em: 11 nov. $2010 b$. 
8. . Resolução CONAMA n. 237, de 19 de dezembro de 1997. Disponível em: <http://www.mma.gov.br>. Acesso: 09 de setembro de 2010.

9. CAGNIN, C. H. Fatores relevantes na implementação de um sistema de gestão ambiental com base na Norma ISO 14001. 2.000. Dissertação (Mestrado em Engenharia da Produção) - Universidade Federal de Santa Catarina, Florianópolis.

10. GIL, Antonio Carlos. Métodos e técnicas de pesquisa social. 5. ed. São Paulo: Atlas, 1999.

11. HOLME, Richard; WATTS Phil. Corporate social responsibility: making good business sense. World Business Council for Sustainable Development, 2000. Disponível em: < http://www.wbcsd.org/DocRoot/lunSPdIKvmYH5HjbN4XC/csr2000.pdf>. Acesso em: 05 set. 2009.

12. IBGE - Instituto Brasileiro de Geografia e Estatística. Censo 2010. Disponível em < http://www.ibge.gov.br/cidadesat/painel/painel.php?codmun=241200>. Acesso em: 08 fev. 2011.

13. KOHLRAUSCH, A. K; ET AL. Selos ambientais: qual seu papel e influência no processo de compra de produtos orgânicos? In: Encontro Nacional de Engenharia de Produção, 24, 2004. Anais... Florianópolis: ABEPRO, 2004.

14. MACEDO, R. G; PIMENTA, H. C; GOUVINHAS, R. P. Gestão ambiental de resíduos sólidos industriais: proposição de um modelo de gerenciamento para indústria de tintas em Natal-RN. In: ENCONTRO NACIONAL DE ENGENHARIA DE PRODUÇÃO, 28, 2008, Rio de Janeiro. Anais ... Rio de Janeiro: ABEPRO, 2008.

15. PIMENTA, H. C. D; MARQUES JUNIOR, S. Modelo de gerenciamento de resíduos sólidos: um estudo de caso na indústria de panificação em Natal-RN. In: ENCONTRO NACIONAL DE ENGENHARIA DE PRODUÇÃO, 26, 2006. Anais ... Fortaleza: ABEPRO, 2006.

16. PRIMOLAN, Luiz Valdeci. A responsabilidade social corporativa como um fator de diferenciação na competitividade das organizações. Revista Gerenciais, São Paulo, v. 3, p. 125-134, out. 2004.

17. ROHRICH, S. S.; CUNHA, J. C. A proposição de uma taxonomia para a análise da gestão ambiental no Brasil. Revista de Administração Contemporânea, v. 8, n. 4, 2004.

18. SCHENINI, P. C.; NASCIMENTO, D. T. Gestão pública sustentável. Revista de Ciências da Administração - v.4, n.08, jul/dez 2002. 
19. SCHNEIDER, Evania Gestão Ambiental Municipal: estudo de caso na Administração Municipal de Teutônia, Porto Alegre: UFRGS/PPGA, 2001.

20. SEIFFERT, M. E. B. ISO 14001: Sistemas de gestão ambiental. São Paulo: Atlas, 2005.

21. SILVA, E. L.; MENEZES, E. M. Metodologia da pesquisa e elaboração de dissertação. 2 ed. Florianópolis: Laboratório de Ensino a Distância da UFSC, 2001. 120 p.

22. SOUZA, R. S. de. Evolução e condicionantes da gestão ambiental nas empresas. Revista - Edição especial 30, v. 8, n. 6, nov.-dez. 2002.

23. STRAUCH, Manuel. Instrumentos da política ambiental. In: STRAUCH, Manuel; ALBUQUERQUE, Paulo Peixoto de. (Org.). Resíduos: como lidar com recursos naturais. São Leopoldo: Oikos, 2008.

24. QUINTAS, J. S. A questão ambiental: um pouco de história não faz mal a ninguém. Brasília: IBAMA, 1992. Mimeo.

25. YIN, Robert K. Case Study Research: Design and Methods. Newbury Park: SAGE, 1994. 